\title{
0984. Perfusate from lungs ventilated ex-vivo with high tidal volumen induce in vitro endotelial dysfunction reversed by superoxide dismutase and tempol
}

\author{
L Martínez-Caro ${ }^{1,2^{*}}$, I Ortiz ${ }^{1,3,4}$, A Sanchez-Ferrer ${ }^{1,2}$, Y Rojas ${ }^{1,2}$, L Smit ${ }^{5}$, B de Olaiz-Navarro ${ }^{1,3}$, A Ferruelo ${ }^{1,2}$, N Nin ${ }^{6,7}$, \\ A Esteban ${ }^{1,2}$, JA Lorente ${ }^{1,2}$
}

From ESICM LIVES 2014

Barcelona, Spain. 27 September - 1 October 2014

\section{Introduction}

Ventilator-induced lung injury (VILI) has been related not only to pulmonary injury but also to systemic damage. We performed a bioassay using ex vivo models of VILI and of vascular function in order to determine the role of pulmonary-derived factors in ventilator-induced endothelial dysfunction. The involvement of nitro-oxidative stress was also examined [1].

\section{Objectives}

(i) To demonstrate that the release of soluble factors derived from the lung induces vascular endothelial dysfunction.

(ii) To define the role of nitro-oxidative stress in ventilator-induced endothelial dysfunction.

\section{Methods}

Ex vivo ventilated and perfused lungs (Harvard Apparatus, MA) from male Sprague-Dawley rats (weight 325-375 grams) were subjected to high tidal volume $\left(\mathrm{V}_{\mathrm{T}}=25 \mathrm{~mL} / \mathrm{kg}\right.$ $+\mathrm{PEEP}=0 \mathrm{~cm} \mathrm{H} \mathrm{H}_{2} \mathrm{O}$ ) mechanical ventilation for $2.5 \mathrm{~h}$ $(\mathrm{n}=22)$. Lungs were perfused $(4 \mathrm{~mL} / \mathrm{min})$ with Krebs solution $+4 \%$ albumin (bubled with $5 \% \mathrm{CO}_{2}$ and $20 \% \mathrm{O}_{2}$ ) that was recirculated throughout the experiment. Aortic rings extracted from healthy rats were incubated in an organ bath for 60 minutes with the perfusate collected from the ventilated lungs. Endothelium-dependent relaxation was measured in norepinephrine precontracted rings

${ }^{1}$ Centro de Investigación Biomédica en Red de Enfermedades Respiratorias (CIBERES), Getafe, Spain

Full list of author information is available at the end of the article (acetylcholine, $10 \mathrm{nM}-10 \mathrm{uM}$ ). Superoxide dismutase (SOD $100 \mathrm{u} / \mathrm{ml}$ ) or tempol

$\left(10^{-4} \mathrm{M}\right)$ (extracellular and intracellular superoxide scavengers, respectively) or MnTMPyP $\left(10^{-5} \mathrm{M}\right)$ (a superoxide and peroxynitrite scavenger), were added to the organ bath in order to explore the role of nitro-oxidative stress in vascular dysfunction. Dose-response curves were compared by repeated-measurements ANOVA. We followed the Principles of Laboratory Animal Care (2010/63/ UE 22-09, RD 53/2013 BOE 1-02, ley 32/2007 BOE 7-11).

\section{Results}

High $\mathrm{V}_{\mathrm{T}}$ mechanical ventilation was associated with an increase in peak airway pressure (PIP), as well as increased levels of LDH, CK and lactate in the perfusate at the end of the experiment, in approximately half of the high $\mathrm{V}_{\mathrm{T}}$ ventilated lungs $(n=10)$, whereas half of the isolatedperfused lungs did not show any changes in PIP, LDH, CK and lactate after $2.5 \mathrm{~h}$ of high $\mathrm{V}_{\mathrm{T}}$ mechanical ventilation $(n=12)$. The perfusate collected from the lungs that showed increased PIP induced an impairment in vascular responses in vitro. On the contrary, the perfusate collected from lungs that did not show an increase in PIP did not induce significant changes in vascular responses in aortic rings. Impaired-responses to acetylcholine were improved by the administration of tempol and SOD, but not by MnTMPyP, to the organ bath $(\mathrm{n}=12-15$ rings per treatment).

\section{Conclusions}

(i) Factors released from injured lungs ex vivo are able to induce endothelial dysfunction in vitro. 
(ii) Oxidative stress is involved in endothelial dysfunction induced by high $\mathrm{V}_{\mathrm{T}}$ mechanical ventilation.

\section{Grant acknowledgment}

FIS 12/02898, FIS 11/02791, FIS 12/02451, European Network (7th FP) ITN 264864, CA11/00260

\section{Authors' details}

${ }^{1}$ Centro de Investigación Biomédica en Red de Enfermedades Respiratorias (CIBERES), Getafe, Spain. ${ }^{2}$ Hospital Universitario de Getafe, Intensive Care Service and Burn Unit, Getafe, Spain. ${ }^{3}$ Hospital Universitario de Getafe, Getafe, Spain. ${ }^{4}$ Hospital Virgen de la Salud, Pediatric Intensive Care Service, Toledo, Spain. ${ }^{5}$ Universidad Alfonso X, Madrid, Spain. ${ }^{6}$ Hospital de Torrejon, Intensive Care Service, Madrid, Spain. ${ }^{7}$ Hospital Español, Intensive Care Service, Montevideo, Uruguay.

Published: 26 September 2014

\section{Reference}

1. Martínez-Caro L, et al: Int Care Med 2009, 35:1110-9.

doi:10.1186/2197-425X-2-S1-P69

Cite this article as: Martínez-Caro et al:: 0984. Perfusate from lungs ventilated ex-vivo with high tidal volumen induce in vitro endotelial dysfunction reversed by superoxide dismutase and tempol. Intensive Care Medicine Experimental 2014 2(Suppl 1):P69.

\section{Submit your manuscript to a SpringerOpen ${ }^{\mathcal{O}}$ journal and benefit from:}

- Convenient online submission

- Rigorous peer review

- Immediate publication on acceptance

- Open access: articles freely available online

- High visibility within the field

- Retaining the copyright to your article 